
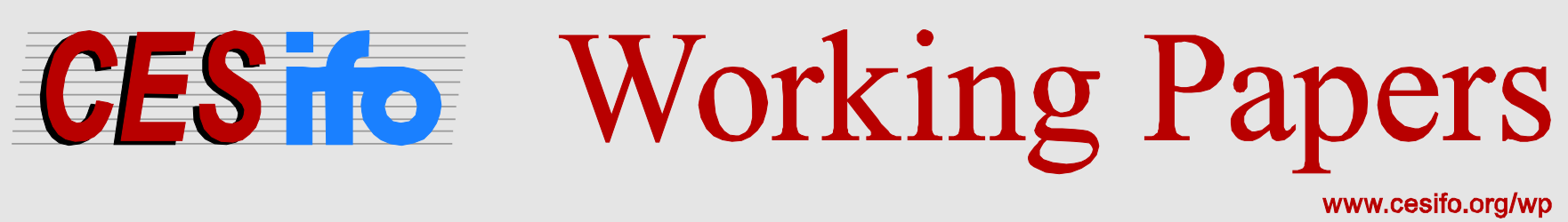

\title{
Reflections on the International Coordination of Carbon Pricing
}

\author{
Ian W. H. Parry
}

\author{
CESIFO WORKING PAPER NO. 5975 \\ CATEGORY 10: ENERGY AND ClimATE ECONOMICS \\ JUNE 2016
}
An electronic version of the paper may be downloaded
- from the SSRN website:
- from the RePEc website:
- from the CESifo website:
www.SSRN.com
www.RePEc.org
www.CESifo-group.org/wp




\title{
Reflections on the International Coordination of Carbon Pricing
}

\begin{abstract}
The efficiency effects of carbon pricing depend on how it impacts distortions in fossil fuel markets, most notably from local air pollution externalities. By offsetting these distortions, carbon pricing may generate significant net economic benefits, so it is in countries own interests to implement carbon pricing unilaterally rather than waiting for others to act. Net benefits are further enhanced if carbon pricing is revenue neutral and broader taxes cause substantial avoidance and evasion. Flexible international pricing regimes, allowing countries with high domestic environmental benefits or fiscal needs to set higher carbon prices, are more efficient than globally uniform carbon prices.
\end{abstract}

JEL-Codes: Q540, Q580, H230.

Keywords: carbon pricing, non-carbon externalities, air pollution, welfare effects, international price floors, fiscal linkages.

Ian W. H. Parry

Fiscal Affairs Department

International Monetary Fund

Washington D.C. / USA

iparry@imf.org

I am grateful to Steven Stoft for valuable comments on an earlier draft. 


\section{INTRODUCTION}

This short paper makes two basic points about international coordination of carbon pricing.

The first is that just because climate externalities cause a global free rider problem (i.e., the reluctance of one country to move ahead unilaterally with carbon pricing because it bears the costs while all countries benefit from a more stable global climate system), this does not mean we have to solve that problem to make a good start on reducing climate externalities. In fact, a significant amount of carbon pricing is in many countries own national interests (before even counting the global climate benefits) because the domestic environmental benefits (most importantly public health benefits from reduced local air pollution), and perhaps also the domestic fiscal benefits, easily outweigh the climate mitigation costs. So countries can move ahead on their own with carbon pricing and make themselves better offthey do not need to wait for large emitters to act in a coordinated way. This is an important message policymakers need to communicate to legislators, the general public, and stakeholders as they start to move forward on their mitigation pledges for the 2015 Paris Agreement on climate change.

The second point is that, as countries seek to build upon domestic pricing initiatives through international coordination, they should consider the possibility of international carbon price floor arrangements (in preference to linked trading systems). These arrangements provide some protection against free rider issues and losses in competitiveness, while allowing individual countries the flexibility to set prices higher than the floor, which can make sense if they have relatively high domestic environmental benefits, high fiscal needs, or if higher prices are more politically acceptable in that country than in other countries. Some operationalizing issues need to be worked out (e.g., accounting for broader changes in energy taxes and subsidies and country-level needs for special provisions in carbon pricing programs) but the practicalities should be manageable.

The following two sections elaborate on the above points.

\section{Is CARbon Pricing in COUNTRIES OWn InTERests?}

The main focus of this section is on the domestic environmental benefits of carbon pricing ${ }^{1}$ as the evidence on their magnitude is more solid than for the fiscal benefits (i.e., the

\footnotetext{
${ }^{1}$ Other mitigation instruments - coal taxes, emission rate standards for power generation, clean fuel subsidies, and so on-may also have domestic environmental benefits. However, there is broad acceptance among analysts, governments, and business that carbon pricing is (by far) the most efficient instrument for reducing $\mathrm{CO}_{2}$ emissions (see www.carbonpricingleadership.org/carbon-pricing-panel) and to maintain a tight focus the discussion here is limited to carbon pricing.
} 
economic efficiency benefits from substituting carbon taxes for distortionary taxes on labor, consumption and capital).

\section{A. Domestic Environmental Considerations}

Leaving aside the global climate benefits, carbon pricing can generate substantial domestic environmental benefits, most importantly the reduction in premature deaths from exposure to local air pollution as carbon pricing reduces the use of coal and other polluting fuels and (less importantly) the reduction in traffic congestion, accidents, and road damage externalities, to the extent carbon pricing reduces vehicle use and these externalities are not reflected in road fuel excises. ${ }^{2}$

Clearly, there are much more efficient instruments than carbon pricing for addressing these domestic environmental externalities. For example, the most efficient way to reduce local air pollution is to impose a Pigouvian tax, either through directly charging emissions, or (which may be administratively easier for some countries) an upfront tax on fuel use combined with rebates for entities demonstrating emissions capture during the combustion process. And (for given road infrastructure) traffic congestion is most efficiently addressed through congestion fees on busy roads, rising and falling progressively over the course of the rush hour.

It is also very clear, however, that it will take a long time before these ideal charging systems are widely implemented across large carbon emitting countries. No country has yet introduced a comprehensive set of charges on the major air pollutants with charges aligned to estimates of air pollution costs ${ }^{3}$ (technology mandates and other regulations are common but they do not fully internalize the externality - see below). And certainly no country comes anywhere near close to having a set of finely-tuned congestion fees, varying with marginal external costs across time of day, on all links in the road network with non-free flowing traffic.

For the interim therefore, it is entirely appropriate to account for the unpriced domestic environmental benefits when assessing the welfare effects of near-term carbon pricing schemes. Not doing do violates long-established principles of welfare measurement ${ }^{4}$ implying that the welfare impacts of new charges in fuel markets hinge critically on preexisting distortions in those markets, whether they be from prior fuels taxes, externalities, or other sources.

\footnotetext{
2 The discussion in this subsection draws from Parry, Heine, and Veung (2014).

${ }^{3}$ See Parry et al. (2014).

${ }^{4}$ For example, Harberger (1964).
} 


\section{Methodology for Measuring Domestic Environmental Benefits}

The conceptual framework for assessing the domestic efficiency benefits (or costs) of carbon pricing is basically straightforward. Consider Figure 1 which shows the demand and supply ${ }^{5}$ for a fuel product like coal or gasoline. In the absence of any non-carbon externalities, preexisting fuel taxes or subsidies, or other distortions, the welfare cost of a new carbon charge in this market is the usual red triangle - the 'Harberger triangle' — with base equal to the reduction in fuel use induced by the carbon charge and height equal to the carbon charge, that is, the fuel's $\mathrm{CO}_{2}$ emissions factor times the charge on $\mathrm{CO}_{2}$ emissions.

If there are non-internalized, non-carbon externalities associated with use of the fuel however, like local air pollution damages, then it is possible for the carbon charge to generate a net welfare gain, indicated by the blue trapezoid in Figure 1, equal to the (non-internalized) domestic environmental benefits - damages per unit of fuel use times the reduction in fuel use-less the Harberger triangle. The prospects for an overall welfare gain in the fuel market are clearly greater (i) the greater the size of the non-carbon externality, relative to the carbon charge, and (ii) the less any internalization of the externality through pre-existing fuel taxes.

\section{Figure 1. Welfare Effect of a Carbon Charge in a Fuel Market}

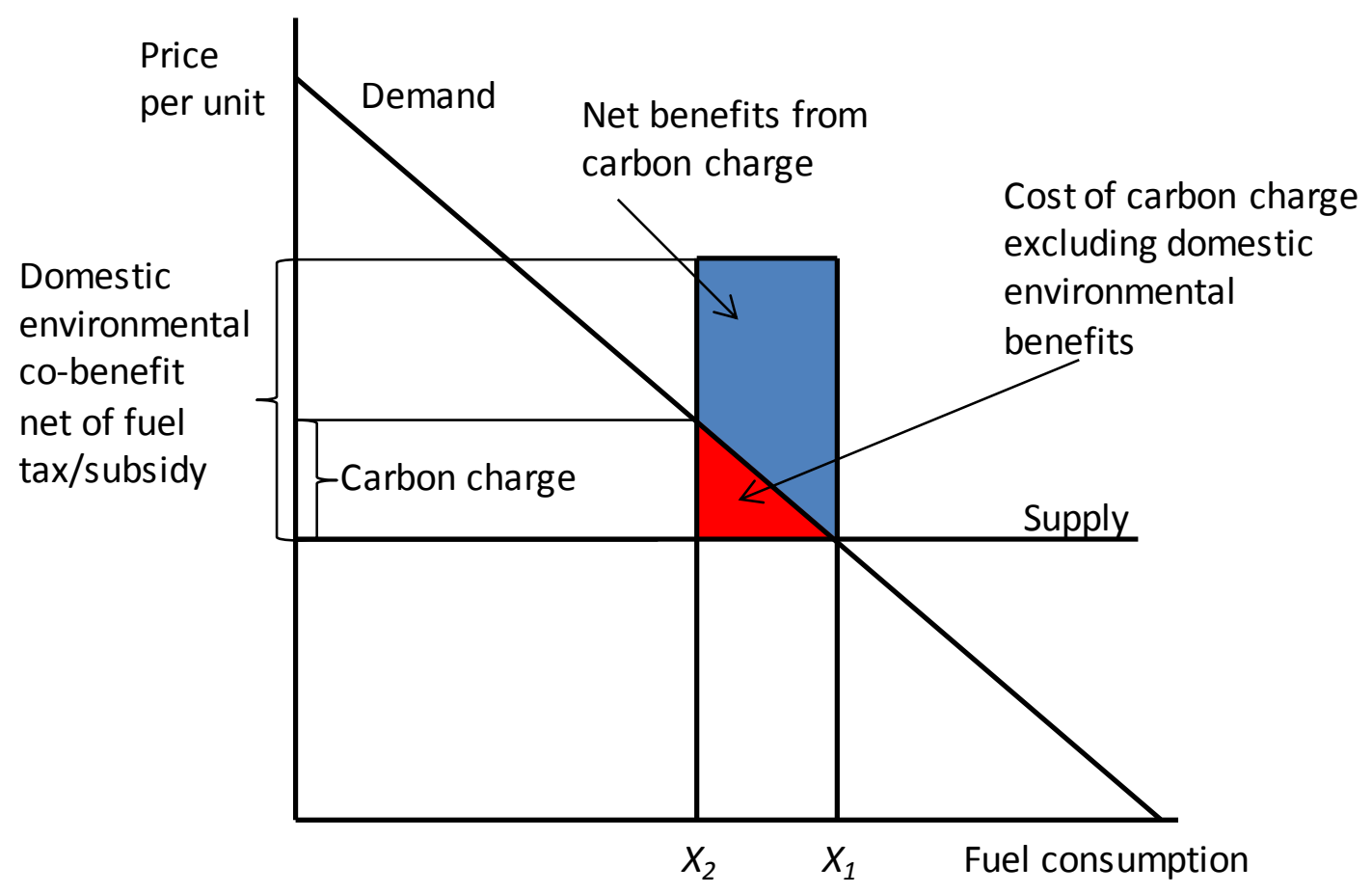

\footnotetext{
${ }^{5}$ The latter is drawn as perfectly elastic, which is generally a reasonable approximation over the longer run.
} 
In fact, if the fuel is subsidized rather than taxed-as has (at least up until recently) been the case for petroleum products and natural gas in a number of Middle East and North African countries $^{6}$ - and if a carbon charge were superimposed on top of unreformed subsidies, the prospects for a welfare gain are further enhanced. On the other hand, while coal and natural gas are generally not subject to substantial excises, road fuels in most countries are, and in cases (e.g., some European countries) where they may exceed estimates of non-carbon environmental costs, carbon charges will induce welfare losses in road fuel markets, despite domestic environmental benefits.

Of course many countries are using domestic (usually regulatory) measures to reduce air emission rates, but this does not eliminate the domestic efficiency gains from carbon pricing. This point is illustrated in Figure 2 where a regulation, like requirements for technologies on new coal plants to reduce sulfur dioxide emissions, shifts up the industry average supply curve (inclusive of technology operation costs) for coal generation and shifts down the industry average environmental damages per unit of coal use, but not to zero. For example, plants operating these technologies still emit some sulfur dioxide, the technologies may not always be switched on, older plants may not have these technologies, and plants produce other air emissions like nitrogen oxides and direct fine particulates. The carbon charge still has the potential to induce a net welfare gain (again indicated by the blue trapezoid), albeit a smaller one than in the absence of other regulations.

Figure 2. Prior Air Pollution Regulation and the Welfare Effect of a Carbon Charge

\footnotetext{
${ }^{6}$ See Clements et al. (2013), Coady et al. (2015).
} 


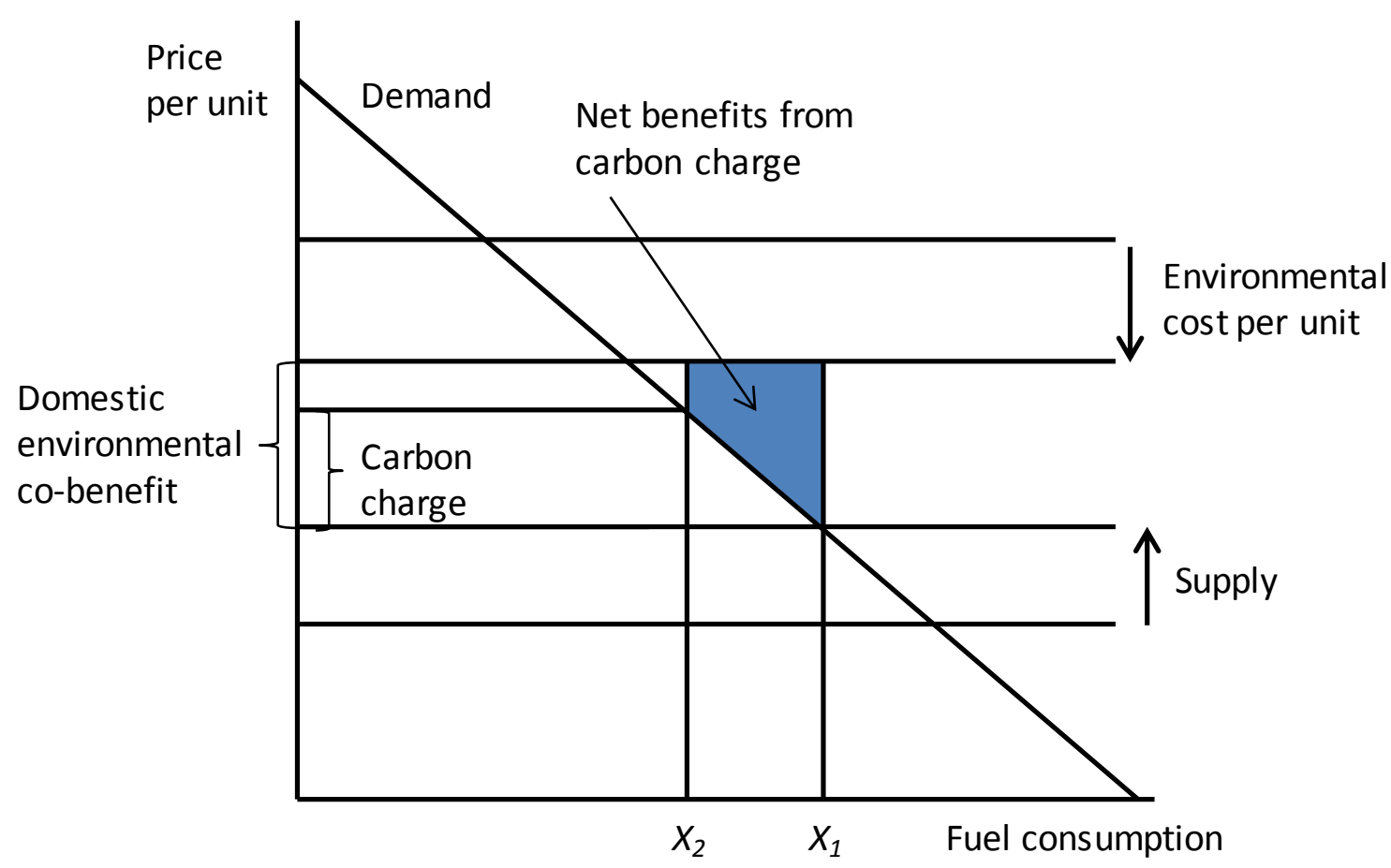

The (second-best) nationally efficient carbon price - that is, the price warranted by domestic environmental benefits (before counting global climate benefits) - is obtained by differentiating the sum of welfare gains (or welfare losses) in the markets for coal, natural gas, and petroleum products with respect to the carbon price. Not surprisingly, the efficient tax (see Parry, Heine, and Veung 2014) is higher (i) the greater the magnitude of non- $\mathrm{CO}_{2}$ externalities net of any prior fuel taxes, and (ii) the greater the share of $\mathrm{CO}_{2}$ reductions that come from fuels with relatively high non-internalized environmental damages.

Parry, Heine and Veung (2014) estimated nationally efficient carbon prices for large emitters for year 2010 using fuel consumption data (from the International Energy Agency), fuel price and tax/subsidy data (from IMF sources), $\mathrm{CO}_{2}$ emissions factors for fuels ${ }^{7}$, fuel price elasticities from the empirical literature ${ }^{8}$, and estimates of domestic environmental costs by fuel product and by country from an IMF database developed by Parry et al. (2014) ${ }^{9}$ - the

\footnotetext{
${ }^{7}$ These are well established and (per unit of energy for coal and natural gas and per liter for petroleum products) vary very little across countries.

${ }^{8}$ Parry, Heine, and Veung (2014) used price elasticities of -0.25 for coal and natural gas and -0.5 for road fuels for each country. Although elasticities are uncertain, and will vary somewhat across countries, typically the estimates of nationally efficient carbon prices are only moderately sensitive to different assumptions. For example, if coal is more price responsive this will tend to raise the nationally efficient carbon price through increasing the share of $\mathrm{CO}_{2}$ reductions coming from coal, which generally has relatively high domestic environmental costs.

${ }^{9}$ The database is available at www.imf.org/environment.
} 
Appendix to this paper provides more details on the measurement of these environmental costs.

Ideally estimates of nationally efficient carbon prices would be projected forward (say to 2030, a typical year for meeting countries' emissions pledges for Paris), accounting for future changes in the fossil fuel mix, changes in fuel prices (which affect the proportionate change in fuel prices from carbon pricing), tightening domestic environmental regulations, rising valuations of air pollution mortality risks with growth in per capita income, and so on. Nonetheless, the estimates discussed below are still useful in providing some broad sense of the size of domestic environmental benefits and the extent of variation across countries.

\section{Results}

Figure 3 shows estimates of nationally efficient carbon prices for the top twenty emitting countries in 2010. These indicate the price levels up to which incremental increases in prices are in countries' own interests because the extra domestic environmental benefits outweigh the extra mitigation costs - only beyond these prices do incremental abatement costs start to rise above domestic environmental benefits (the point at which, in theory, the free rider problem should start to kick in).

While the precise numbers in the figure should not be taken too literally, the two key points are first that the nationally efficient $\mathrm{CO}_{2}$ prices can be substantial and second that the efficient prices differ greatly across countries.

Averaging over the top twenty, the nationally efficient price is $\$ 57$ per ton of $\mathrm{CO}_{2}$ which is a large number - about 60 percent higher than the social cost of carbon in 2010 according to US IAWG (2013).

For China the nationally efficient $\mathrm{CO}_{2}$ price is $\$ 63$ per ton, which essentially reflects the domestic air pollution benefits from reducing coal use - these benefits are relatively high given that China is densely populated with a lot of exposure to coal plant emissions. ${ }^{10}$ Even though air pollution deaths per unit of coal combustion is dramatically lower in the United States (about one-twelfth of that for China) the nationally efficient $\mathrm{CO}_{2}$ price is still $\$ 36$ per ton, in part because the valuation of health risks is assumed to be about four times higher for the United States than for China, and a more significant portion of the $\mathrm{CO}_{2}$ reductions come from reductions in road fuels which are substantially undertaxed from a domestic perspective in the United States.

\footnotetext{
${ }^{10}$ As noted in the Appendix, air pollution damages are conservatively estimated in the sense that emissions rates are based on those at representative plants with emission control technologies rather than the industry average (which is higher due to the inclusion of other plants without control technologies).
} 
Figure 3. Nationally Efficient $\mathrm{CO}_{2}$ Prices, 2010

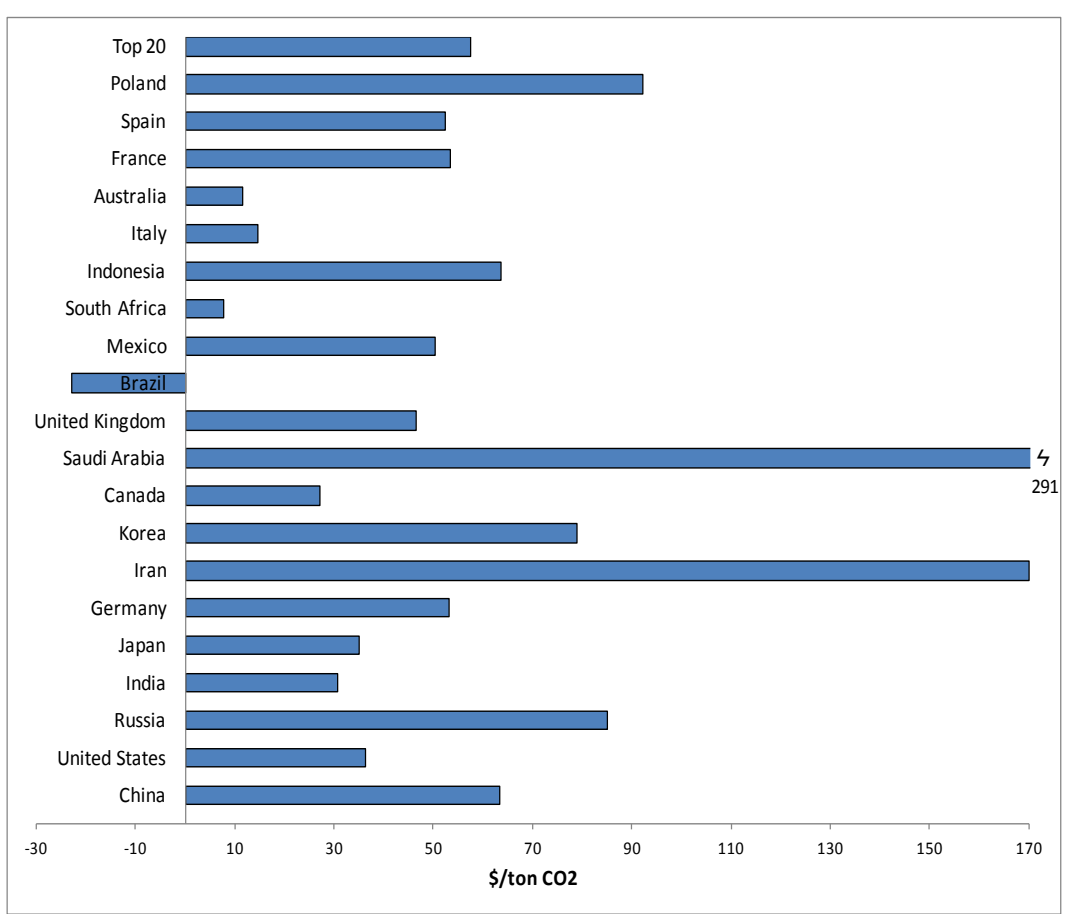

Source. Parry, Heine, and Veung (2014).

Note. Top 20 averages across countries weighting by their emissions shares.

On the other hand, the nationally efficient $\mathrm{CO}_{2}$ price is more moderate in Australia at $\$ 12$ per ton, in part reflecting the much more limited exposure to air pollution (due to low population density and the coastal location of power plants where much of the emissions disperse harmlessly over the oceans). The nationally efficient $\mathrm{CO}_{2}$ price is negative for Brazil, where there is little coal use, and a significant portion of the $\mathrm{CO}_{2}$ reduction comes from reduced gasoline use, which is already overtaxed from a domestic perspective. Also striking are Saudi Arabia and Iran where domestic subsidies for petroleum and natural gas were very large in 2010, implying very large efficiency gains in the (unlikely) event that carbon pricing were imposed on top of unreformed subsidies (though both countries have since been scaling back these subsidies).

\section{B. Fiscal Considerations}

Besides environmental impacts, carbon pricing also raises substantial amounts of revenue, for example, the carbon prices shown in Figure 3 would have raised estimated revenues averaging 1.9 percent of GDP across the top twenty emitters in 2010 (Parry, Heine, and Veung 2014). This raises the issue of whether-leaving aside environmental benefits - raising these revenues from carbon pricing imposes lower costs on the economy than raising them through broader 
fiscal instruments. If so, fiscal considerations constitute another reason why carbon pricing is in countries own domestic interests.

The combined effect of broader fiscal instruments, including personal income taxes, payroll taxes, corporate income taxes, and general consumption taxes, is to distort the economy in two main ways. First, they reduce the overall level of economic activity by reducing real factor returns, thereby deterring work effort and investments in human and physical capital. Second, they distort the composition of economic activity by shifting activity to the informal sector and promoting excessive spending on tax favored goods (e.g., housing, untaxed fringe benefits). In measuring the efficiency costs of broader taxes it is standard to capture (in a reduced form way) both types of distortion, by estimating the responsiveness of the tax base to higher tax rates (e.g., Saez et al. 2012).

Carbon taxes interact with these broader distortions from the fiscal system in two ways. First, using the revenues from carbon pricing to cut the rates of broader taxes produces efficiency gains - termed the 'revenue-recycling effect' - and a key theme of the literature is that these efficiency gains are relatively large, so forgoing them (e.g., through using revenues for low value spending or giving away free allowances in trading systems) greatly increases the overall costs of carbon pricing for the economy (e.g., Parry, Williams, and Goulder 1999). Second, by increasing energy prices and thereby reducing overall economic activity, carbon taxes tend to compound some of the distortions created by broader taxes - the 'tax-interaction effect'.

Up to a point, the revenue-recycling effect tends to dominate the tax-interaction effect, implying a negative cost from carbon tax shifts. This is because cutting broader taxes alleviates distortions both in the overall level of economic activity and its composition, while (loosely speaking) higher energy prices compound distortions to the level of economic activity but not its composition. The prospects for negative costs are greater when the composition effect accounts for a substantial portion of the overall efficiency costs of broader taxes, which can apply to countries with large informal sectors (many developing countries) or with large preferences in the tax code (e.g., the United States). ${ }^{11}$ Accurately quantifying the efficiency gains from carbon tax shifts, and at what carbon price the incremental efficiency impact changes from positive to negative, is however hampered by lack of systematic empirical work across countries on the absolute efficiency costs of broader taxes, and the relative contribution of the level and composition effects. However, some very rough calculations in Parry, Heine, and Veung (2014) suggest that the efficiency gain could, for some countries, be as large as the efficiency benefits from addressing domestic environmental benefits.

\section{The Bottom Line}

\footnotetext{
${ }^{11}$ See, for example, Parry and Bento (2000), Bento et al. (2012).
} 
The bottom line from the above discussion is that many countries can start the process of fulfilling their emissions mitigation pledges for the Paris Agreement through unilateral carbon pricing that addresses local (environmental and fiscal) needs, while also contributing to relieving a global problem - it is not necessary to wait for other countries to act on carbon pricing.

Or viewed another way, once an international agreement to enhance and strengthen domestic initiatives has been implemented, it might be a little less challenging to enforce it than previously thought, because countries make themselves worse off by reneging on the agreement. And the costs of reneging to the general public might be highly visible, for example, in the form of more severe air pollution in emerging market economies where urban residents see, and deal with the health effects of, polluted air on a daily basis and air pollution statistics are routinely reported, or in the form of higher direct and indirect taxes that might be needed to compensate for scaling back a large revenue stream from carbon pricing.

But what form should such an international agreement take?

\section{The Rationale for, ANd Design of, Carbon Price Floor Arrangements}

\section{A. Rationale}

Underpricing from an international perspective is familiar from situations where countries compete for mobile tax bases, in which context some progress has been made through tax agreements, for example, in the European Union for value added taxes and excises on alcohol, tobacco, and energy products. A key lesson here is that it seems easier for countries to agree on tax floors rather than tax rates, not surprisingly given, for example, heterogeneity among countries in the public health benefits from these taxes (depending on the prevalence of smoking, alcohol abuse, and so on), their fiscal needs, and the political acceptability of higher taxes.

The carbon pricing analog would be a coordinated $\mathrm{CO}_{2}$ price floor among a coalition of willing countries, which could be pursued alongside the Paris process. This arrangement would provide some degree of protection for industries competing with imports from other countries that are party to the agreement, and some protection against free riding and crossborder fuel smuggling. Yet individual countries could set prices exceeding the floor, which is efficient if they have relatively high domestic environmental benefits or fiscal needs. More generally, the political acceptability of carbon pricing differs considerably across countries and countries which are willing and able to set higher prices should not be held back. In contrast, linked emissions trading systems (in their pure form) impose a uniform price across participating countries, and policies (e.g., the UK carbon tax floor) to raise the overall 
domestic carbon price in one country will only reduce allowance prices without any effect on system-wide emissions, which are fixed by the regional cap.

\section{B. Design Practicalities}

A carbon price floor agreement could initially be negotiated among a limited number of willing (preferably large emitting) countries and progressively expanded over time with additional participants. ${ }^{12}$ The arrangement could accommodate both countries with carbon taxes and with trading systems, though in the latter case the systems would need to have explicit mechanisms that permanently withdraw allowances from the system to prevent the price falling below a target level. ${ }^{13}$

One challenge is how to account for idiosyncratic, special provisions among countries with carbon pricing programs, like exemptions or reduced rates for influential or vulnerable sectors. Another is how to account for changes in existing energy taxes or subsidies that can enhance, or offset, the emissions impact of a direct price on carbon.

In principle, both challenges could be addressed through monitoring 'effective carbon prices', which convert direct carbon pricing programs and existing taxes/subsidies on fossil fuel products, electricity, and possibly other products (e.g., vehicles) into an aggregate carbon price. This involves converting all carbon pricing schemes and broader energy taxes/subsidies into an economy-wide average carbon price equivalent. For a carbon price scheme with incomplete coverage, the price needs to be weighted by the fraction of emissions reductions that would come from the covered sector under economy-wide pricing. ${ }^{14}$ For broader taxes/subsidies on energy products, these should be converted to carbon price equivalents by dividing the tax/subsidy rate by $\mathrm{CO}_{2}$ emissions per unit of the

\footnotetext{
${ }^{12}$ Starting out with a limited number of countries should improve prospects for an agreement. For example, the European Energy Tax Directive specifying minimum taxes for fuels outside of the EU emissions trading system was implemented just prior to the large expansion in the number of EU member states. Later attempts to reform the Directive have stalled due to the difficulty of reaching agreement among many member states with highly divergent priorities.

${ }^{13}$ The agreement could be made even more flexible by allowing countries to fall short of the price floor in a particular year providing they purchase sufficient carbon credits from countries exceeding the floor price (see Cramton et al. 2016).

${ }^{14}$ For example, if a carbon price is applied to the power and large industry sector and this sector accounts for 50 percent of $\mathrm{CO}_{2}$ emissions, but (due to relatively low cost mitigation opportunities) 75 percent of the $\mathrm{CO}_{2}$ reductions that would occur under economy-wide pricing, then the carbon price should be weighted by 0.75 rather than 0.5 .
} 
product, and then weighting by the share of reductions that would come from that product under economy-wide carbon pricing. ${ }^{15}$

Figure 4 shows some calculations of effective carbon prices across selected countries for 2010. The calculations are highly simplified - just accounting for taxes/subsidies on fossil fuel products ${ }^{16}$ - and somewhat outdated (e.g., Mexico and Indonesia have since scaled back fuel subsidies) but the main point here is that effective carbon prices differ substantially across countries. For example, effective $\mathrm{CO}_{2}$ prices are relatively high (over $\$ 40$ per ton) in France, where road fuels account for a relatively high share of nationwide emissions and there are already high road fuel excises, but effective carbon prices are below $\$ 10$ per ton in most other cases. Given such wide dispersion, achieving convergence in effective carbon prices is likely impractical. But nor is it desirable, as fuel taxes may in part be addressing domestic environmental and fiscal needs, rather than $\mathrm{CO}_{2}$ emissions.

Instead, an agreement might focus on raising effective carbon prices in each country by a target amount (e.g., \$20 per ton in 2020 and $\$ 70$ per ton by 2030) relative to the effective price in that country in a (previous) baseline year. Effective carbon prices would need to be independently assessed, and consistently measured across countries, though the practicalities should be manageable once countries have agreed to analytical conventions (e.g., over fuel price responsiveness assumptions).

\section{Conclusion}

This paper pushes back on two notions about global carbon policy implied by economic models that do not account for non-internalized, non-carbon externalities in fossil fuel markets and broader distortions to economic activity from the fiscal system.

The first is the rather pessimistic notion that acting unilaterally on carbon pricing inevitably makes an individual country worse off, and as a consequence, meaningful progress on carbon pricing will not occur until a pricing agreement among large emitters with credible enforcement mechanisms is in place. In contrast, this paper argues that carbon pricing is in many countries own national interests when account is taken of non-internalized local externality benefits which (up to a point) exceed domestic mitigation costs. Fiscal considerations re-inforce this argument, to the extent that the efficiency costs of raising

\footnotetext{
${ }^{15}$ For example, if electricity generation accounts for 40 percent of economy-wide $\mathrm{CO}_{2}$ emissions but reductions in electricity demand would account for only 10 percent of $\mathrm{CO}_{2}$ reductions under economy-wide carbon pricing, then any tax on electricity use (which only reduces emissions through reducing electricity demand) should be weighted by 0.1 rather than 0.4 .

${ }^{16}$ See OECD (2015) for a more sophisticated treatment.
} 
revenues from carbon pricing are initially lower than those for broader fiscal instruments (when the full range of distortions created by the latter are properly considered).

Figure 4. Effective Carbon Prices, Selected Countries 2010

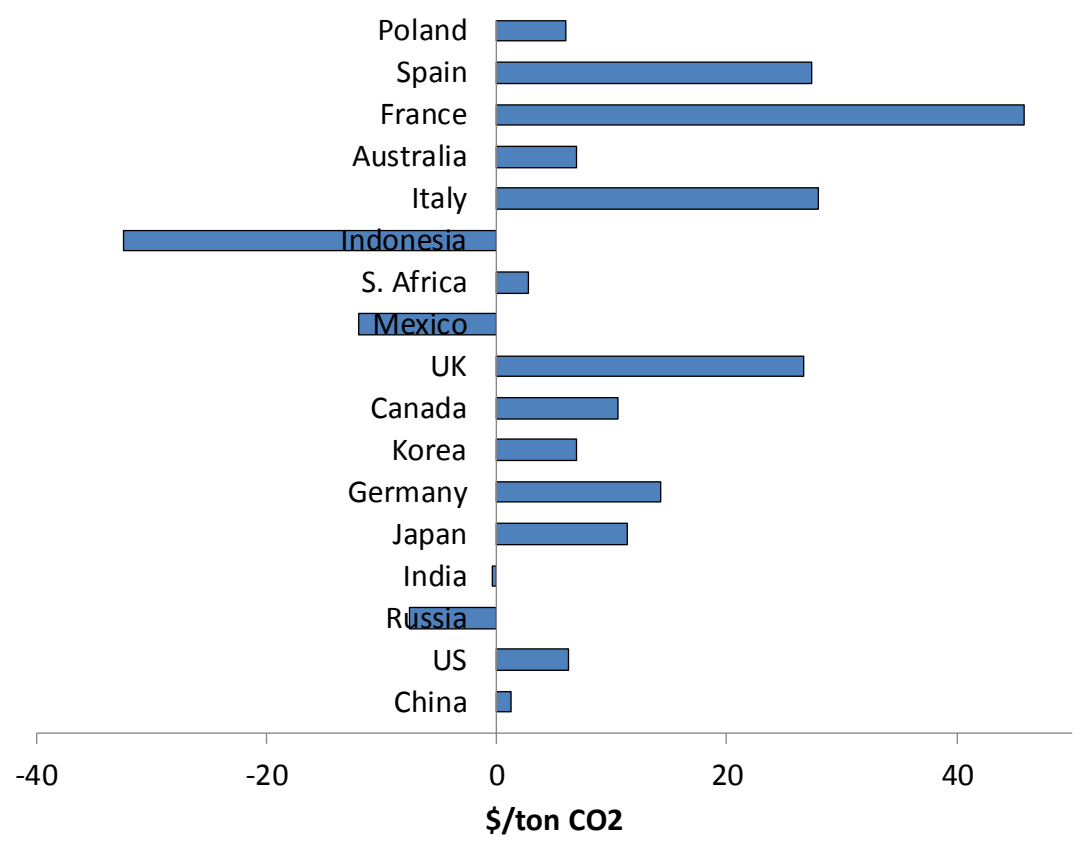

Source. Author's calculations using data compiled in Parry, Heine, and Veung (2014).

It is not inconceivable that policymakers can get these important, but arcane-sounding points across to stakeholders with more accessible messages about estimated lives saved from breathing healthier air, improvements in their international urban air quality rankings, specific commitments to cut burdensome taxes or address underinvestment in hospitals, schools, and infrastructure, with the proceeds from carbon pricing, and so on. In this way, significant headway on carbon pricing at the local level might be made, while at the international level policymakers and organizations continue dialogue on the practicalities of coordinated regimes for eventually building upon local pricing initiatives.

The second notion is that the long term goal should be a uniform global carbon price. That has always looked impractical, given the principle of common but differentiated responsibilities, and the reluctance (especially in current times of historically high fiscal pressures) of advanced countries to transfer large side payments to developing countries that might otherwise be unwilling to impose the same carbon price. A key point from the current paper is that a globally uniform carbon price is not economically efficient either, given the wide dispersion across countries in the magnitude of non-carbon externalities from fuel use and the dim prospects as far as the eye can see for perfectly internalizing them through other pricing policies, as well as differences in the efficient amount of carbon pricing from a fiscal perspective. 
In short, there are both pragmatic and economic arguments for flexible international regimes built around carbon price floor arrangements. Discussions about these regimes should be welcomed by delegates to the annual UN Framework Convention on Climate Change meetings as they would complement and strengthen the mitigation commitment process already initiated by the landmark 2015 Paris Agreement.

\section{References}

Bento, Antonio, Mark Jacobsen, and Antung A. Liu, 2012. "Environmental Policy in the Presence of an Informal Sector.” Discussion paper, Cornell University.

Brauer, Michael, Markus Amann, Rick T. Burnett, Aaron Cohen, Frank Dentener, Majid Ezzati, Sarah B. Henderson, Michal Krzyzanowski, Randall V. Martin, Rita Van Dingenen, Aaron van Donkelaar, and George D. Thurston, 2012, "Exposure Assessment for Estimation of the Global Burden of Disease Attributable to Outdoor Air Pollution," Environmental Science and Technology 46, 652-60.

Clements, Benedict, David Coady, Stefania Fabrizio, Sanjeev Gupta, Trevor Alleyene, and Carlo Sdralevich, eds., 2013. Energy Subsidy Reform: Lessons and Implications. Washington: International Monetary Fund.

Coady, David, Ian Parry, Louis Sears, and Baoping Shang, 2015. "How Large Are Global Energy Subsidies?” Working Paper 15/105, International Monetary Fund, Washington.

Cramton, Peter, Axel Ockenfels and Steven Stoft, 2016. "An International Carbon Price Commitment Promotes Cooperation.” In P. Cramton, D. MacKay, A. Ockenfels, and S. Stoft (eds.), Global Carbon Pricing: We Will if You Will, MIT Press, Cambridge, MA, forthcoming.

Harberger, Arnold C., 1964. "The Measurement of Waste.” American Economic Review 54: $58-76$.

Organization for Economic Cooperation and Development (OECD), 2015. Taxing Energy Use 2015: OECD and Selected Partner Economies, OECD Publishing, Paris, France.

Parry, Ian W.H. and Antonio M. Bento, 2000. "Tax Deductions, Environmental Policy, and the "Double Dividend" Hypothesis." Journal of Environmental Economics and Management 39: 67-96. 
Parry, Ian W.H., Roberton C. Williams and Lawrence H. Goulder, 1999. "When Can Carbon Abatement Policies Increase Welfare? The Fundamental Role of Distorted Factor Markets." Journal of Environmental Economics and Management 37: 52-84.

Parry, Ian W.H., Chandara Veung, and Dirk Heine, 2014. "How Much Carbon Pricing is in Countries' Own Interests? The Critical Role of Co-Benefits." Working paper 14174, International Monetary Fund, Washington, DC.

Parry, Ian W.H., Dirk Heine, Shanjun Li, and Eliza Lis, 2014. Getting Energy Prices Right: From Principle to Practice. International Monetary Fund, Washington, DC.

Saez, Emmanuel, Joel Slemrod, and Seth H. Giertz, 2012. "The Elasticity of Taxable Income with Respect to Marginal Tax Rates: A Critical Review." Journal of Economic Literature 50: $3-50$.

United States Inter-Agency Working Group (U.S. IAWG), 2013. "Technical Update of the Social Cost of Carbon for Regulatory Impact Analysis Under Executive Order 12866." Washington.

\section{Appendix. Procedures for Measuring Domestic Environmental Externalities}

\section{Air Pollution Damages from Coal Plants}

Parry et al. (2014) used four main steps to quantify the air pollution damage from coal plants.

First, data on the geographical location of coal plants in different countries was mapped to very granular data on the number of people living at different distance classifications from each plant (up to 2,000 km away, given the potential long-range transport of emissions from tall smokestacks). This data is used to extrapolate 'intake fractions' - the average portion of a particular pollutant that ends up being inhaled (as fine particulates) by exposed populationsfor different pollutants, from a widely cited study for China, adjusting for population exposure in other countries relative to that in China. Although this approach does not account for differences in meteorological conditions (e.g., wind speeds) between other countries and China, which affects regional pollution formation, some cross-checks with air quality models in a limited number of cases suggest the bias from omitting these factors is not necessarily large and does not follow a systematic pattern.

The second step is to obtain elevated mortality risks by country from additional pollution emissions by linking intake fractions to two pieces of information from the Word Health Organization's Global Burden of Disease project. One is baseline mortality rates in different regions for illnesses (heart, pulmonary, and lung diseases and strokes) whose prevalence is 
increased by exposure to pollution. ${ }^{17}$ The other is evidence on the relationship between pollution exposure and additional mortality risk, or 'concentration-response' functions. ${ }^{18}$ One noteworthy issue here is that, although at lower pollution concentrations the concentrationresponse function is approximately linear, some (though not all) evidence suggests it may flatten out at especially severe concentration levels as people's channels for absorbing pollution become saturated. Paradoxically, this would imply (given other factors) lower marginal environmental benefits for small pollution reductions in severely polluted regionsthis possibility is not taken into account in the estimates presented here.

The third step is to monetize mortality risks. For this purpose, Parry et al. (2014) use estimates of the value per premature mortality for the average OECD country ( $\$ 3.7$ million, updated to 2010 ) and of the elasticity of mortality valuation with respect to income (0.8) - both based on the literature - to extrapolate mortality values for all countries.

The final step is to convert damages per ton of emissions into damages per unit of coal use using a country-level database of coal plant air emissions factors compiled by the International Institute for Applied Systems Analysis. The results presented above are based on those for a representative sample of plants with emissions control technologies and are therefore lower than the industry average emission rates (the latter including plants with no control technologies), a possible justification being that industry average emission rates will gradually converge to the former over time as older, dirtier plants are retired from the fleet.

\section{Air Pollution from other Sources}

The same steps as above were used to assess environmental damages for natural gas used in power generation.

Local air emissions from ground-level sources - principally vehicles and residential heatingtend to stay locally concentrated (rather than being transported long distances) which simplifies assessment of their intake fractions. Parry et al. (2014) obtain (from other studies) ground-level intake fractions for air emissions from over 3,000 cities, extrapolate these to the country level, and then follow the last three steps mentioned above.

\section{Other motor vehicle externalities}

In the absence of better data, Parry et al. (2014) regress travel delays from a city-level database on various transportation indicators and then extrapolate delays to the national level using the

\footnotetext{
${ }^{17}$ Mortality rates are relatively high in Eastern Europe where there is high consumption of alcohol and tobacco, and relatively low in African countries where people are more prone to dying from other non-pollution-related diseases.

${ }^{18}$ The key assumption here is that each 10 microgram/cubic meter increase in fine particulate concentrations increases all-cause mortality risks by 10 percent, which is similar to assumptions used in modelling by the US Environmental Protection Agency.
} 
regression coefficients and country-wide measures of those same indictors. Marginal delay (the delay one extra kilometer driven in one vehicle imposes on other road users) is assumed to be four times the average delay, loosely based on specifications commonly used by transportation engineers. The result is scaled by vehicle occupancy, and monetized based on literature suggesting the value of congested travel time is around 60 percent of the wage. These estimates likely understate marginal congestion costs, for example, cars impose greater delay to other road users when buses (which have high vehicle occupancies) are a significant share of vehicles on the road.

Parry et al. (2014) estimate accident externalities by country using data on people killed in traffic accidents and assumptions about the decomposition between internal and external risks, for example, injury risks to occupants in single-vehicle collisions are assumed to be internal, while risks to pedestrians/cyclists and a portion of injuries in multi-vehicle collisions, are taken to be external. Other components of external costs (e.g., medical and property damages borne by third-parties, a portion of non-fatal injuries) are extrapolated from several country case studies. Road damage costs, which apply to heavy (diesel) vehicles are obtained from data on road maintenance expenditures (where it is available and extrapolated from other countries where it is not) and assumptions about the portion of wear and tear due to vehicle traffic as opposed to other factors like climate.

Mileage-related externalities (congestion, accidents, road damage, and local pollution where emissions regulations are expressed on a per mile basis) are scaled back by around 50 percent in computing Pigouvian taxes, given that only about half of the long run reduction in fuel use from higher road fuel taxes comes from reductions in vehicle mileage (the other half coming from long-run improvements in average fleet fuel economy which essentially have no effect on mileage-related externalities). 